\title{
English Language Challenges among Students of Princess Aisha Bint Al-Hussein College of Nursing \& Health Sciences at Al-Hussein Bin Talal University
}

\author{
Reem Rabea \\ Al-Hussein Bin Talal University, Jordan \\ Nusaiba Adel Almahameed \\ Al-Hussein Bin Talal University, Jordan \\ Ahmad H. Al-Nawafleh \\ Mutah University, Jordan \\ Jawad Obaidi \\ University of Putra, Malaysia
}

\begin{abstract}
The aim of the current study is to investigate the perceived learning challenges as well as the coping strategies employed by Nursing and Health Sciences (NHS) students at Al-Hussein Bin Talal University (AHU) in dealing with general and medical English as a foreign language in the learning process. Princess Aisha Bint Al-Hussein College of Nursing \& Health Sciences (PAC) at AHU needs to address these challenges to meet the low-level grades of its students. A three-part questionnaire was used for data collection over a time period of three consecutive academic semesters. It is a 26-item self-reported questionnaire with a 5-point Likert-type scale. Statistical Package for Social Science (SPSS) was used for statistical analysis. The reliability of the scale was tested using Cronbach alpha. The outcomes showed that the students struggle with the issue of limited language proficiency. This problem, then, which the study's outcomes present is twofold: firstly, due to the students' lack of knowledge and proficiency in general English and secondly, because of students' lack of proficiency in medical English. Actually, students are not only burdened by the fact that they lack the proficiency of general English but further by their unfamiliarity with medical English.
\end{abstract}

Index Terms-Nursing, Health Sciences, English Language, challenges, coping strategies, Al-Hussein Bin Talal University

\section{INTRODUCTION}

English holds a prominent and prestigious position being the universal or world language that is used as the language of communication and instruction in many contexts globally, and it is therefore a necessity. In this specific vein, a recent joint study by the British Council and The University of Oxford asserts that "there is a fast-moving worldwide shift from English being taught as a foreign language (EFL) to English being the medium of instruction for academic subjects" (Dearden, 2014, p. 2). In Jordan, alongside the official language, Arabic, English is predominantly considered to be the second language of instruction. It is the compulsory foreign language to be taught in the Jordanian public and private schools, starting from the elementary school where students start to study English in KG1 until the last level of the secondary education. Regardless of this formal teaching of English, the level of competence is very low amongst students upon joining university study. This is due to the dominance of Arabic daily conversations and the lack of enough exposure to English speaking and use in daily life during this stage. In a study to examine the general difficulties faced by Arab students in Jordan, Saudi Arabia and Egypt Suleiman (1983) argues that the prevalent dissatisfaction with the entire output of Arab learners in English subjects was due to, among many others, inadequate essential principles in curriculum conception and design, lacking in-classroom approaches as well as the slow progress in the students' communication skills (cited in Intakhab Alam Khan, 2011, p. 71).

Furthermore, English is used as a language of instruction in the areas of science and technology (medicine, engineering, pharmacy, health sciences and nursing, computer science and information technology, biology, physics, chemistry, etc.). Thus, if a student is enrolled in higher education institutions to specialise in one of these subjects, s/he is expected to use English widely and extensively since the learning process based completely on U.S and British textbooks. 
Predominated by these expectations and requirements, Health Science education is graded as one of the most enduring and challenging trainings to pursue. The language challenges a health science student encounters during his/ her undergraduate years are numerous. English language as a foreign language utilised as a medium of instruction is one of the challenges that stresses nursing and health science NHS students. Coping with medical English as an instrument for learning is another challenge for NHS students and almost a second language in itself. NHS students are usually challenged by the fact that they have to learn, study, negotiate, participate and respond to examination in English during learning at college.

According to the discussion above, this study aims to explore the perceived language challenges as well as the coping strategies utilised by NHS students at AHU. It addresses the language challenges experienced by students using English as a foreign language in the learning process. According to the researchers' knowledge, this study is considered to be one of the pioneering studies that deal with this issue in Jordan.

\section{BACKGROUND}

Students of medical and health related professions in higher education institutions in Jordan are taught in English. Students' expected level of English that allows them to be accepted at the university is supposed to be satisfactory. The universities assess students' level of English to study any university programme by examining the competency of English in general. Students outside the university do not use English in their daily life. Nevertheless, in clinical settings and during practice and training they communicate with the staff and their clinical instructors in English and mainly use the medical terminology. Medical terms are Latin in origin and purely English. The patients' charts and documentation of the practice is usually written in English. The programme's exams are offered in English. On the other hand, communication with patients and their relatives usually proceed in Arabic, as well as the routine and informal daily conversations among staff.

When the health related programmes curriculum in Jordan was designed, it was mainly based on American programmes as the instructors were qualified there. The instructors mainly adopted programmes of their institutions where they did their doctoral degrees. The curriculum was not based on attracting international students; neither to prepare national students for the global labour market; nor to raise the profile of the institution (Doiz, et al., 2011, p. 347). Regardless of that, the graduates of the medical and health related professions programmes are prepared mainly to work in Jordan and in the region where Arabic is the native language of the population. Therefore, the implementation of English as medium of instruction raises diverse questions regarding the linguistic competence of the teachers' to deliver the courses in English, the students' understanding of the course content of knowledge, and the skills and attitudes or the possible effect of English medium instruction on the quality of the programmes and their outputs (Doiz, et al., 2011, p. 347).

\section{LITERATURE REVIEW}

A considerable amount of research has been done and demonstrated the several challenges English-as-a-Foreign Language (EFL) students in the specialisations of Nursing and Health Sciences encounter during their learning process. Language is viewed as a challenge in several studies which implemented quantitative reports (Guhde, 2003; Labun, 2002; Sanner, Wilson, \& Samson, 2002; Shakya \& Horsfall, 2000; Starr, 2009; Veal, 2012; Villarruel, Canales, \& Torres, 2001; Villarruel \& Peragallo, 2004; Yoder, 2001). Starr (2009) contends that language, including reading, writing, comprehension, and communication, is one of nursing education challenges which significantly impacts resources, academics, and cultural issues with English as an additional language (EAL). Students who have only a conversational command of English but lack the basic English skills needed to be successful in the academic and scientific setting.

Most of these studies have dealt with EFL students in English speaking countries focusing chiefly on nursing students. Glew, (2013); Guhde, (2003); Salamonson et al., (2011); Sanner \& Wilson, (2008); and Shakya \& Horsfall, (2000) have done studies applied on nursing students in Australia and the United States and have found that EFL nursing students are inclined to have difficulties with general and medical English, which may impact their academic performance and also require more efforts than students who are native speakers of English. Glew addresses the challenges of using academic English as an additional language experienced by students during their nursing studies in the Australian tertiary learning setting. He contends that students' success in a nursing programme necessitates EAL students to fulfill significant literacy skills in English and academic language through their learning process. In particular, Glew (2013) has considered the education significances for nursing programmes and developing literacy skills through the preregistration phase "to meet the English language skills standard for nurse registration and presents intervention strategies for nursing programmes" which propose to build EAL student capability in using academic English (p. 101). Moreover, according to Boughton et al. (2010) and Jeong et al. (2011) EFL students need to demonstrate a high level of academic standing to fulfill their commitments in the nursing programme and perform at the anticipated level in the clinical positions. Students working in the clinical setting encounter difficulties in interacting with colleagues, patients and their families. In considering international students' experience of second language and 
academic stress, Khawaja et al. (2017) observe that international nursing students often encounter second language anxiety and are even subject to academic stress particularly with reference to its spoken aspect (603).

Unfortunately there is a serious lack of research done on the challenges EFL students encounter in NHS education when English is the language of instruction in non-English speaking countries in general and in Arab countries in particular. In fact, a study has been done by Suliman and Tadros (2011) to examine the strategies used by nursing students to cope with English as a foreign language medium of instruction especially when Arabic is the mother tongue. Their study has been applied to students in the College of Nursing at King Saud Bin Abdulaziz University for Health Sciences in Saudia Arabia. The study argues that nursing students' success in college is extremely reliant on their ability to cope well with their stress of studying in English and surmount the difficulties facing them in communicating orally and in writing in English. The study shows how nursing students adopted and incorporated a number of coping strategies to assist them overcome their learning difficulties including "self-controlling, seeking social support, planful problem-solving, and positive reappraisal" which change over the course of the study and used according to the stressful situation and the challenges experienced each time (4). Abushaikha et al. (2014) has conducted a study on Jordanian male nursing students that explores the challenges students encounter during the course of their study. The study investigates the several academic difficulties that male students faced with English as the language of instruction highlighting issues such as "preparing for examinations, demanding clinical rotations, difficulties in registering for courses online" (Abushaikha et al, 2014, p. 265).

EFL students in NHS programmes are usually subject to challenges most importantly language difficulties; both in general and medical English which hinder their academic progress in the educational setting. The issue of language difficulties among college students has been a topic of interest and a key concern of researchers for several years; because a lot of the research has been done in English speaking countries. Olson (2012) identified the several reasons for EFL nursing students' often struggle in nursing programme and among them are the language barriers. Olson classifies the reasons in four categories but identifies the issue of "English language deficiency" as the most important and salient barrier. She contends that "language barriers were identified as the single most significant obstacle facing the EFL nursing student" (26).

Philips and Hartley (1990) pointed out that the language difficulties nursing students encounter may influence their academic achievement. They have remarked that for students to succeed in the healthcare environment, they must master the four language skills. They also noted that, in the medical field, more challenging is the students' need to learn the medical terminology and how incorporate it in their learning process in addition to the requirement to be skilled in the language itself. In other words, proficiency required in everyday language is utterly separated from the one required in medical language. In this particular vein, Guhde (2003) asserts that EAL students "must learn medical terminology" in order to obtain a higher level of textual as well as oral communication as academic problems are often directly connected with language difficulties (p. 14).

Heming and Nandagopal (2012) have conducted a survey on the medical curriculum of EFL students in the premedical years in a country where Arabic is the mother tongue. Students were asked to recognise all unknown words in the text. They emphasise that the success in medical studies "requires an understanding of both technical (scientific/ medical) and non-technical (general) vocabulary" (p. 486). They assert that ESL medical students find difficulties in understanding technical words rather than non-technical words. They add that the reason behind the difficulty that Arab ESL students facing in comprehending scientific/ medical statements are due to the weaknesses in their understanding of general vocabulary. In this respect, Glew (2013) contends that "[h]aving an adequate knowledge of academic language and proficiency in English for tertiary studies can determine the success of EAL students in a nursing programme" (p. 102). By the same token, Wang, et al., (2008) observes that universities offering education for these students "may not fully appreciate the student's needs and are therefore inadequately prepared to provide them with a tailored, quality educational experience" (p. 140). Furthermore, Suliman and Tadros (2011) affirm that despite the fact that universities can provide nurse education programmes that satisfy the teaching and learning needs of home students (native speakers of English), they may be devoid of the adult literacy programming ability to efficaciously improve the English and academic language skills of EAL students for nursing. In the same context, Crawford and Candlin (2013) assert that state that one of the language challenges ESL students encounter during their learning process relates to the higher level of academic English demanded in higher education, in addition to the medical language used in healthcare. They confirm that the nature of the tasks which include analysis, synthesis and evaluation is another challenge, along with the requirements discussed above (pp. 182-183).

According to the preceded discussion, English is frequently viewed as a challenge for English-as-a-Foreign Language (EFL) students as several studies and scholarly work observe its impact on the academic achievement of NHS students. The previous studies investigate the issue of English as a significant academic challenge concentrating on specific language skills. Students do not only require basic English skills but also need to be successful in the academic and scientific setting. In addition to the previous studies, this study will consider the various challenges NHS students face with using general and medical English as a medium of instruction, which may influence their academic performance and also require more efforts than students who are native speakers of English. The study will also expose to the strategies used by NHS students in coping with English as a foreign language medium of instruction when Arabic is the mother tongue. 


\section{ReSEARCH Methodology}

Research Questions:

The study purported to answer the following research questions:

RQ1. What are the challenges faced by NHS students at AHU using English as the language of instruction?

RQ2. What are the predominant strategies utilised by NHS students at AHU students to cope with English as a foreign language?

Research instrument and data collection method:

A three-part questionnaire was used for data collection. Part one is intended to obtain background information of demographic factor. It comprises five questions covering the subjects of student's age group, their gender, specialisation, their level of study, and whether or not they passed the English Language Level Test. Part two investigates the English language challenges that face NHS in PAC at AHU during their learning process. Finally, part three presents the strategies utilised to address the challenges.

It is a 26 item self-reported questionnaire with a 5-point Likert-type scale. The scale indicates the level of which each of the items is utilised by the respondents, using the following response scales: $1=$ strongly disagree, $2=$ disagree, $3=$ Neutral, 4 = agree, and 5= strongly agree. The reliability of the instrument, using Cronbach's alpha, demonstrates an acceptable degree of stability.

This descriptive structured questionnaire was used over a time period of three consecutive semesters. A translation of the questionnaire into Arabic is made aimed at making it more accessible to the participants, whose native language is Arabic.

Population and sample:

A convenience sampling was recruited from NHS students of different levels in their nursing education at the time of data collection. Students in Nursing, Radiology, and Medical Analysis educational programmes participated in this questionnaire. Of the 300 students who were invited to take part in the study, only 204 students responded with acceptable inclusion criteria for the analysis. This number represents about $61.2 \%$ of response rate. Table 1 presents the demographic profile of the sample.

TABLE 1

DEMOGRAPHIC ATTRIBUTES OF RESPONDENTS.

\begin{tabular}{|l|l|l|l|}
\hline \multicolumn{1}{|c|}{ Variable } & Attribute & No. of Participants & Percentage \% \\
\hline Gender & Male & 17 & 8.3 \\
& Female & 187 & 91.7 \\
\hline Age & $<20$ & 109 & 53.4 \\
& $21-25$ & 95 & 46.6 \\
\hline Specialisation & Nursing & 95 & 46.6 \\
& Radiology & 36 & 17.6 \\
\hline Level of Study & Medical Analysis & 73 & 35.8 \\
& $1^{\text {st }}$ & 13 & 6.4 \\
& $2^{\text {nd }}$ & 69 & 33.8 \\
& $3^{\text {rd }}$ & 36.3 \\
\hline Did you pass the English Language Level Test? & $4^{\text {th }}$ & 46 & 22.5 \\
& $5^{\text {th }}$ & 2 & 1.0 \\
\hline
\end{tabular}

Reliability of the instrument

Statistical Package for Social Science (SPSS) was used for statistical analysis. The reliability of the scale was tested using Cronbach alpha. The questionnaire's internal consistency and clarity were measured was measured by a test employed on 15 students using test-retest with two-week interval in between. The table below shows the coefficients and the internal consistency, which is 0.77 for the challenges and 0.81 for the coping strategies. These ratios demonstrate stability and are considered suitable for the purposes of this study.

TABLE 2:

THE INTERNAL CONSISTENCY ACCORDING TO CRONBACH ALPHA.

\begin{tabular}{|l|l|}
\hline Coefficients & Internal Consistency \\
\hline The challenges faced by (NHS) students at (AHU) using English as the language of instruction & 0.77 \\
\hline $\begin{array}{l}\text { The strategies utilised to address the challenges faced by NHS students at AHU using English as } \\
\text { the language of instruction }\end{array}$ & $\mathbf{0 . 8 1}$ \\
\hline
\end{tabular}

Results and Discussion

RQ1: What are the challenges faced by NHS students at AHU using English as the language of instruction?

To answer this question, the means and the standards deviation of the challenges faced by NHS students at AHU using English as the language of instruction were calculated. 
TABLE 3:

THE CHALLENGES FACED BY NHS STUDENTS AT AHU

\begin{tabular}{|l|l|l|l|l|}
\hline RANK & $\#$ & Items & Mean & Standard Deviation \\
\hline 1 & 13 & The unavailability of English training sessions held on campus & 4.12 & 1.157 \\
2 & 8 & $\begin{array}{l}\text { The lack of an English course specified for the Faculty of Princess Aisha Bint } \\
\text { Al-Hussein's students }\end{array}$ & 4.00 & 1.164 \\
\hline 3 & 15 & Reliance on the translated form of exam questions in order to understand them & 3.97 & 1.071 \\
\hline 4 & 11 & Reliance on memorisation in the way of test preparation & 3.93 & 1.081 \\
\hline 5 & 10 & Feeling content with summaries without reading the main references & 3.92 & .989 \\
\hline 6 & 14 & $\begin{array}{l}\text { The Lack of centers or institutes that hold specialised courses in English off } \\
\text { campus }\end{array}$ & 3.88 & 1.181 \\
\hline 7 & 12 & $\begin{array}{l}\text { The lack of a mark specified for participation in lectures since the total mark is } \\
\text { divided as 25 marks for the first exam and 25 marks for the second exam }\end{array}$ & 3.81 & 1.377 \\
\hline 8 & 5 & Inability to write short articles in English & 3.72 & 1.103 \\
\hline 9 & 6 & Embarrassment while using English & 3.70 & 1.143 \\
\hline 10 & 9 & The lack of advance preparation of course & 3.66 & 1.035 \\
\hline 11 & 1 & Lack of proficiency in English & 3.62 & 1.056 \\
\hline 12 & 2 & Lack of proficiency in medical terminology & 3.61 & 1.163 \\
\hline 13 & 7 & Diffidence in speaking English & 3.49 & 1.230 \\
\hline 14 & 16 & The university's environment encourages me to speak in English & 3.29 & 1.495 \\
\hline 15 & 3 & Fear of studying texts written in English & 3.24 & 1.270 \\
\hline 16 & 4 & Inability to understand texts written in English & 3.24 & 1.120 \\
\hline & & TOTAL & 3.70 & .601 \\
\hline
\end{tabular}

As indicated in Table 3, the respondents' mean scores on sixteen items ranged from 4.12 to 3.24. Two of the top sixteen items which received the highest mean scores (ranked thirteenth and eighth) corresponds with the challenges: "The unavailability of English training sessions held on campus" ( $\mathrm{m}=4.12)$ and "The Lack of an English course specified for the Faculty of Princess Aisha Bint Al-Hussein's students" ( $\mathrm{m}=4.00)$, whilst the last two lowest items which ranked third and fourth correspond with the "Fear of studying texts written in English" $(\mathrm{m}=3.24)$ and "Inability to understand texts written in English" $(\mathrm{m}=3.24)$. Those results are attributed to the lack of English training courses whether at the university level or specific to the students' discipline. The students, therefore, encounter the fear of studying in English which also render in their struggle and even inability to understand texts written in English. Moreover, students are also challenged by both their tendency to memorise data in test preparation and reliance on the translated form of exam questions in order to understand them. They depend on memorisation in the way of test preparation and they memorise medical terms without distinguishing what's requested. Their teachers recommend that students in exams memorise and provide general information about terms without providing specific answers.

It is noted that nursing students require to enhance their general and medical English levels. This finding is supported by Starr (2009) who has observed that the challenge of language has a direct impact on students' success or failure particularly as these students are required to learn both general English as well as the technical language practiced in health. Starr argued the ineffectualness of the additional English classes notably the simplicity of content in addition to the nature of context which does not meet students' needs. He has noted that students do not only need to learn English, but also technical English and medical terminology. Table 3 demonstrates that all the means are high and, hence; the predominant challenge that encounters NHS students is the need to have English training sessions held on campus to improve their English. The table also shows that NHS students need special or additional English course specified for them. On the other hand, the study found out that the two lowest challenges confront NHS students are related to the fear they display while studying texts written in English as well as the inability to understand texts written in English. This finding may hint the students' attempt to avert thinking about their fears of studying and understanding English texts. In addition, it may be indictable of the students' restless efforts to overcome their fears and handle stressful situations.

RQ2: What are the predominant strategies utilised by NHS students at AHU students to cope with English as a foreign language?

To answer this question, the means and the standards deviation of the strategies utilised to address the challenges faced by NHS students at AHU using English as the language of instruction were calculated (table 4).

The findings, as observed from Table 4, show that the means of the coping strategies utilised by NHS students to address the challenges they experienced, rank from 4.54 to 3.47. The predominant coping strategies are indicated in "I reject the idea of failing my studies because of the English language" (4.54) and "I try to do my best to overcome the language problem and to get away from the idea of dropping the course" (4.53). The adopted strategies suggest that the majority of NHS students at AHU are revealingly ambitious since they effortlessly attempt to considerably cope with their English struggle. This is apparent in their determination not to consider English as an obstacle in completing their study. It also appears in their persistence to overcome the language barriers and defy the thinking of failing or dropping the course. 
TABLE 4

THE STRATEgIES UTILISED TO AdDREss THE CHALLENGES FACED By (NHS) STUDENTS AT (AHU)

\begin{tabular}{|l|l|l|l|l|}
\hline RANK & $\#$ & Items & Mean & Standard Deviation \\
\hline 1 & 3 & $\begin{array}{l}\text { I reject the idea of failing my studies because of the } \\
\text { English language }\end{array}$ & 4.54 & .646 \\
\hline 2 & 1 & $\begin{array}{l}\text { I try to do my best to overcome the language problem and } \\
\text { to get away from the idea of dropping the course }\end{array}$ & 4.53 & .732 \\
\hline 3 & 2 & $\begin{array}{l}\text { I instill confidence in myself and the perseverance to } \\
\text { achieve my goal }\end{array}$ & 4.49 & .608 \\
\hline 4 & 7 & $\begin{array}{l}\text { I encourage myself to speak in English even when I am } \\
\text { afraid of making a mistake }\end{array}$ & 4.13 & .924 \\
\hline 5 & 10 & I attempt to write in English & 4.09 & .886 \\
\hline 6 & 6 & I watch Television programmes and films in English & 4.05 & 1.040 \\
\hline 7 & 4 & I attempt to translate some texts during my free time & 3.94 & 1.011 \\
\hline 7 & 7 & $\begin{array}{l}\text { I attempt to build up relationships with students whose } \\
\text { English is better than mine }\end{array}$ & 3.94 & 1.128 \\
\hline 9 & 9 & I attempt to speak in English outside lectures & 3.75 & 1.170 \\
\hline 10 & 5 & I join English courses to improve my English. & 3.47 & 1.237 \\
\hline & & Total & 4.09 & .551 \\
\hline
\end{tabular}

On the other hand, the two lowest strategies adopted by the respondents associated with joining English courses to improve English (3.48) and the student's attempt to speak in English outside lectures (3.75). The students' lack of initiative to join English courses in order to improve their English correlates with the predominated challenge of the unavailability of English training sessions held on campus. This is actually due to not only the fact that AHU does not offer or accommodate English training sessions on campus but also to the unavailability of training councils or centres offering English courses in the city of Ma'an, where AHU is located. Furthermore, living where English is not a mother tongue brings respondents further challenges in practicing English both on and off campus.

TABLE (5):

ENGLISH LANGUAGE DIFFICULTY AS ILLUSTRATED BY PARTICIPANTS' ATTRIBUTES

\begin{tabular}{|c|c|c|c|c|}
\hline & & The challenges Mean & Standard Deviation & Valid Percent \\
\hline Gender & $\begin{array}{l}\text { Male } \\
\text { Female }\end{array}$ & $\begin{array}{l}3.28 \\
3.74\end{array}$ & $\begin{array}{l}.529 \\
.593 \\
\end{array}$ & $\begin{array}{l}17 \\
187 \\
\end{array}$ \\
\hline Age group & $\begin{array}{l}<20 \\
21-25\end{array}$ & $\begin{array}{l}3.57 \\
3.84 \\
\end{array}$ & $\begin{array}{l}.612 \\
.556\end{array}$ & $\begin{array}{l}109 \\
95\end{array}$ \\
\hline Respondent's specialisation & $\begin{array}{l}\text { Nursing } \\
\text { Radiation } \\
\text { Laboratory }\end{array}$ & $\begin{array}{l}3.67 \\
3.81 \\
3.69 \\
\end{array}$ & $\begin{array}{l}.641 \\
.455 \\
.611 \\
\end{array}$ & $\begin{array}{l}95 \\
36 \\
73 \\
\end{array}$ \\
\hline level of study & $\begin{array}{l}\text { 1st year } \\
\text { 2nd year } \\
\text { 3rd year } \\
\text { 4th year }\end{array}$ & $\begin{array}{l}3.63 \\
3.62 \\
3.87 \\
3.56 \\
\end{array}$ & $\begin{array}{l}.536 \\
.683 \\
.571 \\
.475\end{array}$ & $\begin{array}{l}13 \\
69 \\
74 \\
48\end{array}$ \\
\hline Did you pass the English level test? & $\begin{array}{l}\text { Yes } \\
\text { No }\end{array}$ & $\begin{array}{l}3.64 \\
3.80\end{array}$ & $\begin{array}{l}.644 \\
.512\end{array}$ & $\begin{array}{l}126 \\
78\end{array}$ \\
\hline
\end{tabular}

Table 5 illustrates variant differences in means and standard deviations of the study's investigation of the challenges NHS students at AHU encounter due to difference in group attributes; gender, Age group, respondent's specialisation, level of study, and whether or not they passed the English Language Level Test.

The female students are found out to be less challenged than males. This variance may be attributed to cognitive linguistic abilities and the fact that females usually present faster language development (Berglund, Eriksson, \& Westerlund, 2005; Hoff, 2013). Moreover, the differences in the challenges are seen in favor of the age group (21-25). This outcome correlates with students' academic levels of study. On the other hand, there are no differences attributed to variations in students' areas of specialisation (Abushaikha et al., 2014; Hoff, 2013). According to students' responses, these language challenges were not specific to particular academic departments; rather, these challenges were common reoccurring phenomena in all departments. The differences between third and fourth-year students are noticed in favor of third year students. Advanced students are found to be less challenged than beginners. This may be attributed to their endurance and persistence to overcome their language challenges which they continued to build throughout their study. This finding is made evident by the students' answers elicited by the questions in part three of the questionnaire.

Furthermore, there are differences between the students who passed the English Language Level Test and those who did not, and they were in favor of those who did not pass the test. The students' failure to successfully pass the English Language Level Test may be attributed to the students' unfamiliarity with computerised tests that are limited by time. The time students allowed to complete their test seems not to be enough. On the other hand, the test given measures only general English skills and cannot be considered as an effective tool to measure the students' knowledge of medical English. The students who failed the test are apparently less challenged by using English as an additional language and managed to do better in their studies. This indicates the inefficiency of the English Language Level Test to evaluate the students' true levels of medical English. Students who fail the test are usually requested to take pre-nursing English 
courses. In this particular vein, a study done by Veal (2012) on the factors affecting linguistically diverse nursing students' and native English speakers' academic success including language abilities, asserts that the pre-nursing English courses do not primarily measure the student's ability to comprehend reading in a social and academic setting. However, the differences are still an issue that needs more elaboration probably by a future study focusing on this issue and the correlation with the medical English.

\section{RECOMMENDATIONS}

On the light of the results of this study, the researchers recommend that the English Language Level Test is seen as generic and lack specificity regarding students' particular departments and academic needs. Therefore, a review of the test's purpose, nature and quality of questions is required. In addition, the researchers observe the necessity of devising special instruction ESP course; zero-credit compulsory module which can address the students' specific needs and meet their particular technical purposes in the English academic context. It is recommended that Al-Hussein Bin Talal University should follow some of the universities in gulf countries and should design ESP course for health sciences students, as for example University of Sharjah in which students of Science in Nursing (BSN) and Medical Laboratory Sciences should undertake a total of 3 credit hours of a course named as English for Medical Sciences.

Students are required to be competent in the language employed in their settings (e.g. medical English) rather than general English. Therefore, the study suggests that some particular language skills of NHS students at AHU can be met through the modification of the teaching strategies and curricula. Finally, more studies are necessitated in association with the issue of challenges NHS students encounter when English used as a medium of instruction in other Jordanian universities.

\section{CONCLUSION}

The purpose of this study was twofold: (1) to identify the several language challenges NHS in PAC at AHU experience during their learning process and (2) explore the strategies utilised by students to address them. Apart from preceding studies, which have chiefly focused on language challenges ESL students encounter while studying Nursing in non-English speaking countries, this study addresses the language problem of ESL students in Nursing as well as Health sciences.

The difficulty of using general and medical English is a prominent issue challenging NHS students while completing their studies and participating effectively in the academic environment. This issue seems to be associated with the higher level of academic language demanded in this subject area along with the medical language used in Health Sciences. For NHS students at AHU, the issue of limited language proficiency is of two parts. It may be due to the students' lack of knowledge and proficiency in general English and because of students' lack of proficiency of medical English. Actually, students are not only burdened by the fact that they lack the proficiency of general English but further by their unfamiliarity with medical English.

The study addressed the challenges NHS students at AHU encounter during their education and identified strategies utilised in response. The study also advocates a few recommendations that attempt to significantly decrease the challenges and overcome the English weaknesses by giving nursing students the academic support needed. Success in learning and coping with English as a foreign language medium of instruction will produce nurses who are competitive and accordingly contribute to better career opportunities and solve the global nurse shortage. The study's findings provided new insights to the current knowledge of the educational experiences of undergraduate NHS students in a developing country. Understanding the challenges as well as the applied coping strategies from the viewpoints of undergraduate NHS students will efficiently help NHS instructors to improve their understanding of their students' educational experiences and elucidate their roles and responsibilities in coping with these issues. Further research is, however, required done to enhance the understanding of the academic challenges and the coping strategies nursing students employ while learning using English as a foreign language medium of instruction.

\section{REFERENCES}

[1] Abushaikha, L., Mahadeen, A., AbdelKader, R., \& Nabolsi, M. (2014). Academic Challenges and Positive Aspects: Perceptions of Male Nursing Students. International Nursing Review, 61(2), 263-269.

[2] Berglund, E., Eriksson, M., \& Westerlund, M. (2005). Communicative Skills in Relation to Gender, Birth Order, Childcare and Socioeconomic Status In 18 - Month - Old Children. Scandinavian Journal of Psychology, 46(6), 485-491.

[3] Boughton, M. A., Halliday, L. E., \& Brown, L. (2010). A Tailored Program of Support for Culturally and Linguistically Diverse (CALD) Nursing Students in a Graduate Entry Masters of Nursing Course: a Qualitative Evaluation Of Outcomes. Nurse Education in Practice, 10(6), 355-360.

[4] Crawford, T., \& Candlin, S. (2013). A Literature Review of the Language Needs of Nursing Students Who Have English as a Second/Other Language and the Effectiveness of English Language Support Programmes. Nurse Education in Practice, 13(3), 181-185.

[5] Dearden, J. (2014). English as a Medium of Instruction-a Growing Global Phenomenon. UK: British Council.

[6] Doiz, A., Lasagabaster, D., \& Sierra, J. M. (2011). Internationalisation, multilingualism and English-medium instruction. World Englishes, 30(3), 345-359. 
[7] Glew, P. J. (2013). Embedding International Benchmarks of Proficiency in English in Undergraduate Nursing Programmes: Challenges and Strategies in Equipping Culturally and Linguistically Diverse Students with English as an Additional Language for Nursing in Australia. Collegian, 20(2), 101-108.

[8] Guhde, J. A. (2003). English-as-a-Second Language (ESL) Nursing Students: Strategies for Building Verbal and Written Language Skills. Journal of cultural diversity, 10(4), 113-117.

[9] Heming, T. A., \& Nandagopal, S. (2012). Comparative Difficulties with Non-Scientific General Vocabulary and Scientific/Medical Terminology in English as a Second Language (ESL) Medical Students. Sultan Qaboos University Medical Journal, 12(4), 485-492.

[10] Hoff, E. (2013). Language Development (5th ed.). Belmont, CA: Wadsworth Cengage Learning.

[11] Jeong, S. Y.-S., Hickey, N., Levett-Jones, T., Pitt, V., Hoffman, K., Norton, C. A., \& Ohr, S. O. (2011). Understanding and Enhancing the Learning Experiences of Culturally and Linguistically Diverse Nursing Students in an Australian Bachelor of Nursing Program. Nurse Education Today, 31(3), 238-244.

[12] Khan, I. A. (2011). Challenges of Teaching/Learning English and Management. Global Journal of Human Social Sciences, $11(8), 68-80$.

[13] Khawaja, N. G., Chan, S., \& Stein, G. (2017). The Relationship Between Second Language Anxiety and International Nursing Students Stress. Journal of International Students. 7(3), 601-620.

[14] Labun, E. (2002). The Red River College Model: Enhancing Success for Native Canadian and Other Nursing Students from Disenfranchised Groups. Journal of Transcultural Nursing, 13(4), 311-317.

[15] Olson, M. A. (2012). English-as-a-Second Language (ESL) Nursing Student Success: a Critical Review of the Literature. Journal Of Cultural Diversity, 19(1), 26-32.

[16] Phillips, S., \& Hartley, J. T. (1990). Teaching Students for whom English is a Second Language. Nurse Educator, 15(5), $29-32$.

[17] Salamonson, Y., Andrew, S., Clauson, J., Cleary, M., Jackson, D., \& Jacobs, S. (2011). Linguistic Diversity as Sociodemographic Predictor of Nursing Program Progression and Completion. Contemporary Nurse, 38(1-2), 84-93.

[18] Sanner, S., \& Wilson, A. (2008). The Experiences of Students with English as a Second Language in a Baccalaureate Nursing Program. Nurse Education Today, 28(7), 807-813.

[19] Sanner, S., Wilson, A. H., \& Samson, L. F. (2002). The Experiences of International Nursing Students in a Baccalaureate Nursing Program. Journal of Professional Nursing, 18(4), 206-213.

[20] Shakya, A., \& Horsfall, J. M. (2000). ESL undergraduate nursing students in Australia: Some experiences. Nursing \& Health Sciences, 2(3), 163-171.

[21] Starr, K. (2009). Nursing education challenges: Students with English as an additional language. Journal of Nursing Education, 48(9), 478-487.

[22] Suliman, W. A., \& Tadros, A. (2011). Nursing Students Coping with English as a Foreign Language Medium of Instruction. Nurse Education Today, 31(4), 402-407.

[23] Veal, J. (2012). Academic Success Factors Influencing Linguistically Diverse and Native English Speaking Associate Degree Nursing Students. (Doctoral dissertation). Retrieved from: https://epublications.marquette.edu/dissertations_mu/242/.

[24] Villarruel, A. M., Canales, M., \& Torres, S. (2001). Bridges and Barriers: Educational Mobility of Hispanic Nurses. Journal of Nursing Education, 40(6), 245-251.

[25] Villarruel, A. M., \& Peragallo, N. (2004). Leadership Development of Hispanic Nurses. Nursing Administration Quarterly, 28(3), 173-180.

[26] Wang, C.-W., Singh, C., Bird, B., \& Ives, G. (2008). The Learning Experiences of Taiwanese Nursing Students Studying in Australia. Journal of Transcultural Nursing, 19(2), 140-150.

[27] Yoder, M. K. (2001). The Bridging Approach: Effective Strategies for Teaching Ethnically Diverse Nursing Students. Journal of Transcultural Nursing, 12(4), 319-325.

Reem Rabea received her PhD in Comparative Literature from Manchester Metropolitan University and is currently an assistant professor at Al-Hussein Bin Talal University. Her research interests include Modern English Novel in the 20th Century, Postcolonial Literature and Postcolonial Theory, Comparative Literature, British Travel Writing in the 19th and 20th Centuries, Postcolonialism and Fin-de-siècle Literature and Culture. Address for correspondence: Al-Hussein Bin Talal University, Department of English Language and Literature, Ma'an, Jordan. P.O. Box 20. Email: reem_rabia@yahoo.co.uk.

Nusaiba Adel Almahameed received her PhD in Modern English Literature from The University of Salford and is currently an assistant professor at Al-Hussein Bin Talal University. Her research interests include modern English literature, Virginia Woolf, Children's literature and Fairy tales. Address for correspondence: Al-Hussein Bin Talal University, Department of English Language and Literature, Ma'an, Jordan. P.O. Box 20. Email: n.almahameed@yahoo.co.uk.

Ahmad H. Al-Nawafleh, (PhD, MPA, CI, RN), has extensive practical experience as a nurse and clinical instructor since his graduation from University of Jordan in 1992. He became an assistant professor at the University of Mutah, Faculty of Nursing, where he taught for seven years in the undergraduate and graduate programmes. Then he was promoted to associate professor in 2015. His nursing research has focused on nursing management, health policy, public health, patient safety, decision making, primary health services and staffing issues. He has presented on these topics at numerous conferences. His abiding passion continues to focus on the recognition and amelioration of staffing and policies, wherever it exists. He currently lives in Mutah, Jordan, where he works as academic and writes about health, leadership, policy, and nursing. 
Jawad Obaidi received his MA in Nursing from Al-Albayt University. He is a passionate oncology nurse with three years of experience as Nurse Specialist in clinical area and over seven years of experience in Academic institutions. His research in terests include quality of life, nursing, education, palliative care, euthanasia, and end of life. Affiliation: He is a PhD Candidate at University of PUTRA in Malaysia. Address for correspondence: Huwarrah, Irbid, Jordan, 21141. Email: jobaidi85@gmail.com. 